Revista Científica General José María Córdova

(Revista Colombiana de Estudios Militares y Estratégicos)

Bogotá D.C., Colombia

ISSN 1900-6586 (impreso), 2500-7645 (en línea)

Web oficial: https://www.revistacientificaesmic.com

\title{
La planeación por escenarios como herramienta para la construcción de paz en el Caquetá
}

\section{Parcival Peńa Torres}

https://orcid.org/0000-0002-1656-7111

pa.pena@udla.edu.co

Universidad de la Amazonia, Florencia, Colombia

\section{Claritza Marlés Betancourt}

https://orcid.org/0000-0002-1314-7517

c.marles@udla.edu.co

Universidad de la Amazonia, Florencia, Colombia

\section{Orlando Valera Alfonso}

https://orcid.org/0000-0002-0359-8074

orlandovalera@infomed.sld.cu

Universidad de La Habana, Cuba

Citación APA: Peña Torres, P., Marlés Betancourt, C., \& Valera Alfonso, O. (2022). La planeación por escenarios como herramienta para la construcción de paz en el Caquetá. Revista Cientifica General José María Córdova, 20(37), 45-67.

https://dx.doi.org/10.21830/19006586.838

Publicado en línea: $1 .^{\circ}$ de enero de 2022

Los artículos publicados por la Revista Cientifica General José María Córdova son de acceso abierto bajo una licencia Creative Commons: Atribución - No Comercial - Sin Derivados.
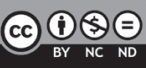

Para enviar un artículo:

https://www.revistacientificaesmic.com/index.php/esmic/about/submissions
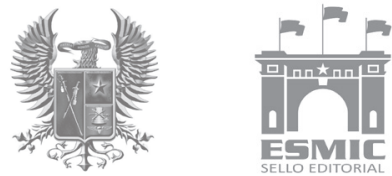


\title{
La planeación por escenarios como herramienta para la construcción de paz en el Caquetá
}

\section{Scenario planning as a tool for peace-building in Caquetá}

\author{
Parcival Peña Torres y Claritza Marlés Betancourt \\ Universidad de la Amazonia, Florencia, Colombia
}

\section{Orlando Valera Alfonso}

Universidad de La Habana, Cuba

RESUMEN. Este artículo busca determinar los escenarios de futuro como una alternativa para la construcción de paz en el Caquetá, una de las regiones más afectadas por el conflicto armado en Colombia y que enfrenta grandes retos en el posconflicto. Para ello se presenta una investigación descriptiva con enfoque mixto basada en las fases de la técnica prospectiva de matriz de impacto cruzado, con una muestra conformada por actores del desarrollo regional de los sectores del saber, del poder, productivo y la comunidad. Los resultados revelan que los eventos de futuro en cuatro dimensiones: capacidades institucionales, problema de cultivos ilícitos, víctimas del conflicto e influencia de la educación superior, constituyen el escenario más dinamizador para la construcción de paz en la región.

Palabras Clave: acuerdo de paz; desarrollo; escenarios; estudios de futuro; prospectiva

ABSTRACT. This article seeks to determine future scenarios as an alternative for peace-building in Caquetá, one of the regions most affected by the armed conflict in Colombia and facing enormous challenges in the post-conflict period. To this end, it presents a descriptive study with a mixed approach based on the phases of the prospective cross-impact matrix technique, involving a sample of regional development actors from the knowledge, power, productive, and community sectors. The results reveal that future events in the dimensions of institutional capacities, illicit crops issues, victims of the conflict, and the influence of higher education, constitute the most dynamic scenarios for peace-building in the region.

KeYwords: development; future studies; peace agreement; prospective; scenarios

Sección: Política y Estrategia • Artículo de investigación científica y tecnológica

Recibido: 20 de junio de 2021 • Aceptado: 6 de octubre de 2021

Contacto: Parcival Peña Torres $\bigotimes$ pa.pena@udla.edu.co 


\section{Introducción}

Este artículo se ubica en un momento histórico que vive Colombia después de un largo conflicto armado y del Acuerdo de Paz en el 2016, que logró definir unos temas centrales sobre las necesidades básicas en lo político, social, cultural, económico y agrario. A partir de ello, se definieron los términos de un posacuerdo, es decir, una etapa de estabilización política, que inicia con la implementación de los acuerdos de paz y la justicia transicional: una etapa que "alude al momento posterior a los pactos de paz" (Ulloa \& Coronado, 2016 p. 32). Alcanzar la firma de un acuerdo de paz es el compromiso de superar el conflicto en todas sus expresiones y darle paso a los conflictos políticos que emergen, para que sean dirimidos por vías democráticas y alternativas (Álvarez-Rodríguez, 2017).

Con ello inició la tarea de los actores del desarrollo regional para garantizar la implementación del Acuerdo, con grandes retos como el surgimiento de nuevos conflictos: conflictos sociales, de intereses políticos, económicos, estructurales, además de la idiosincrasia colombiana, que desborda el alcance del acuerdo mismo (Tiusabá \& López, 2019). En el país, especialmente en Caquetá, se registra la activación de grupos disidentes/reincidentes con hechos de violencia, confrontaciones con otros grupos armados, señalamiento de objetivos militares y economías de guerra. Esto convierte al Caquetá en el quinto departamento más afectado por la reactivación del conflicto, en particular por los frentes guerrilleros 1, 3, 7, 49 y la columna Teófilo Forero en la zona sur del país (Álvarez et al., 2018).

Entre 1989 y 2020 se registra en Colombia un total de 18002 muertes violentas como resultado del conflicto con las FARC, si bien se destaca una disminución de este hecho victimizante desde la firma del Acuerdo de Paz (Uppsala Conflict Data Program, s. f.). Ante este panorama, se debe continuar por un sendero que garantice y conserve el proceso de paz. Una alternativa hacia el futuro es el diseño de escenarios que permitan anticipar las acciones ante la complejidad de la implementación del proceso. Esto se trata no solo de hacer análisis desde las proyecciones estadísticas, económicas y los pronósticos tecnológicos, sino de contemplar la interacción de los cambios que puedan describir la transición del sistema social y vislumbrar un futuro que permita edificar las acciones para obrar en el presente y contribuir en la construcción de paz.

Así, este artículo se propone identificar las dimensiones que influyen en la construcción de paz con sus respectivos eventos de futuro, para que los actores directos e indirectos determinen el grado de influencia a través de la aplicación de la técnica de matriz de impacto cruzado (SMIC), para dar respuesta a la siguiente pregunta de investigación: ¿̨cuáles son los escenarios de futuro en la construcción de paz en el Caquetá? La estructura del documento está orientada a dar respuesta al problema en tres momentos secuenciales: 1) un amplio desarrollo de los estudios de futuro, con la conceptualización de planeación por escenarios, conflicto armado y construcción de paz; 2) construcción de la metodología amparada en la técnica SMIC; y 3) el análisis de datos mediante el aplicativo Smic-Prob Expert. Los resultados identifican cuatro escenarios de futuro que influyen en la construc- 
ción de paz en el Caquetá: capacidades institucionales; solución al problema de drogas ilícitas; víctimas del conflicto, e influencia de la educación superior.

\section{Marco teórico}

\section{Los estudios de futuro}

Los análisis de futuro permiten formular interrogantes acerca de la influencia del pasado, presente y futuro en la toma de decisiones organizacionales, para generar proyecciones a futuro que no son valoradas según la precisión o el cumplimiento irrestricto de los hechos señalados, sino como producto de la participación, la creatividad, la visión integradora que plantean, el mayor entendimiento del presente y el rol activo que se debe tener en él (Hevia, 2000).

De acuerdo con esto, Dator (2019) considera que la prospectiva es la mejor manera de mirar hacia el futuro con el objetivo de lograr apreciar y estudiar lo sucedido en el pasado y los posibles acontecimientos por venir. Igualmente, Miklos y Tello (2000) sostienen que los estudios de futuro constituyen una visión integral de aspectos cuantitativos y cualitativos, con "relaciones dinámicas fundamentadas en estructuras evolutivas con un futuro incierto, no obstante, una actitud hacia el futuro activa y creativa" (p. 21).

A su vez, los estudios de futuro toman un nuevo rol en el presente, ya que están directamente relacionados con aspectos sociopolíticos, influenciados por el contexto cultural y la resistencia al cambio. Diversas metodologías se han contextualizado para comprender el origen y la evolución de los estudios de futuro en las ciencias humanas como su área central, con lo cual se ha reconocido que los cambios económicos, tecnológicos y políticos generan transformaciones significativas para estos estudios; en contraste, los aspectos culturales y psicológicos se toman más tiempo en generar impactos representativos (Concheiro \& Medina, 2013).

En los estudios de futuro existen dos corrientes principales. Primero está la corriente norteamericana, con un dominio tecnológico y énfasis en los objetivos militares, de la cual ha surgido el forecasting como herramienta para pronosticar (Bradfield et al., 2005). Segundo, la corriente europea, que incluye la futurología; la prospectiva orientada al rol y la participación de actores sociales (Berger, 1964; Jouvenel, 1964); la prospectiva estratégica con su caja de herramientas y estrecha relación con la planeación estratégica (Godet, 2000), y la previsión humana, orientada al bien común, la democracia y el liderazgo participativo (Masini, 2011; Medina, 2003).

En efecto, el estudio de futuro comprende características específicas que fortalecen su análisis: la interdisciplinariedad y complejidad (mecanismos para comprender las interrelaciones sociales); la transdisciplinariedad (instrumento para aplicar la complejidad); la globalización (contexto en que se realiza el análisis de futuro); la normatividad (identificación de características de una sociedad y sus desarrollos); la cientificidad (para comprender la forma como evoluciona el futuro generando discusión entre las disciplinas); la dinámica 
(estudia la transformación social y su influencia en escenarios probabilísticos), y la participación (presencia del recurso humano en los proyectos acerca del futuro). Igualmente, este tipo de estudio se enmarca en una metodología extrapolativa, donde se mezcla el conocimiento del pasado y el presente para extrapolarlo e identificar posibles acontecimientos futuros, lo que convierte el método de escenarios en una metodología para describir alternativas de futuro.

\section{Planificación por escenarios}

La planeación por escenarios es una de las técnicas fundamentales en los estudios de futuro que permite preparar, anticipar, cuestionar y pensar creativamente sobre lo que se vislumbra en el futuro y en múltiples futuros posibles, más allá del tendencial (Hiltunen, 2009). La primera definición considera a los escenarios como secuencias hipotéticas de eventos, construidos con el propósito de centrar la atención en los procesos causales y la toma de decisiones (Kahn \& Wiener, 1967). Entre otros, Peña (2008) afirma que el escenario "emplea una gama de técnicas para investigar, recoger ideas y escribir historias en su intento de plasmar en forma narrativa todos aquellos eventos que definan los linderos de los terrenos competitivos del futuro" (p. 178).

El uso metódico de los escenarios para aclarar análisis sobre el futuro inició después de la Segunda Guerra Mundial, cuando el Departamento de Defensa de los Estados Unidos la empleó como metodología de planeación militar en la década de los años cincuenta en RAND Corporation (Kahn \& Wiener, 1967; Bradfield et al., 2005; Durance \& Godet, 2010). A raíz de ello, esta metodología se utilizó ampliamente para la previsión social, el análisis de políticas públicas y la toma de decisiones en la década de 1960. Schoemaker (1993) afirma que la planificación de escenarios debe delinear los futuros posibles, capturar una amplia gama de opciones, estimular el pensamiento sobre el futuro y desafiar la mentalidad prevaleciente y el statu quo. Con la aplicación de los escenarios se puede provocar la reflexión sobre nuevas opciones más allá de la zona de confort operativa y conceptual tradicional de las organizaciones (Brabandere \& Iny, 2010; Chermack, 2004), lo que permitirá explorar nuevos y únicos conocimientos.

Es necesario hacer precisiones sobre el concepto de escenario de futuro, pues hay muchas definiciones e interpretaciones que han generado confusión, pero siempre con la misma finalidad de pensar en el futuro (Khakee, 1991). Al respecto, Bradfield (2004) considera que el concepto de escenario es planeación, imaginación, proyección, análisis y conocimiento; sin embargo, una definición más simplificada es la descripción de un futuro potencial o posible, incluyendo el detalle de cómo llegar a él (Godet, 2006; Blyth, 2005; Porter, 2004). Los escenarios siempre proporcionan una radiografía del contexto donde se evidencian sus relaciones con las tendencias y sucesos que permiten lograr una anticipación creativa e innovadora frente al futuro.

En este punto, es necesario esclarecer la diferencia entre la planificación por escenarios y el desarrollo de escenarios. La primera es una actividad más abarcante que implica 
la realización de un estudio prospectivo completo, mientras la segunda se enfoca en la elaboración de historias específicas acerca del futuro (Gauna et al., 2020).

Por otro lado, la metodología de escenarios crea un contexto futuro que se desarrollaría según su contexto actual y las proyecciones de lo que se quiere lograr en un tiempo dado. Para Godet y Durance (2009), se trata de un método integrador que busca un entorno deseable a partir de algunas especificaciones y que "tiene como objetivo construir representaciones de los futuros posibles y de los caminos que conducen a él” (p. 44).

Este artículo aborda la planificación por escenarios desde la perspectiva metodológica de Godet y Durance (2009) con la aplicación del método de SMIC para identificar los escenarios de futuro en el contexto de la construcción de paz en el departamento del Caquetá, el cual se analiza desde las siguientes seis dimensiones identificadas para el estudio:

- $\mathrm{D}_{1}$. Fortalecimiento de capacidades institucionales de la sociedad civil: Son habilidades desarrolladas durante el conflicto armado, donde las instituciones potencian dos capacidades: específicas, como el conocimiento del terreno y hardware; y las convertibles, orientadas a las redes de apoyo y financiamiento de una organización política (Raymond, 2017).

- $\quad \mathrm{D}_{2}$. Víctimas del conflicto: Con la firma del Acuerdo de Paz se concedió a las víctimas el derecho a la reparación y reconstrucción de una memoria histórica como eje primordial de la transición hacia la paz (Velandia \& Paba, 2021). Esto se promulgó en la Ley 1448 (2011), que define las víctimas como aquellas personas que han sufrido un daño como consecuencia de infracciones al Derecho Internacional Humanitario o de violaciones graves y manifiestas a las normas internacionales de derechos humanos. De acuerdo con Arias (2020), son las víctimas quienes han vivenciado la implementación de los acuerdos, los avances y retrocesos, con las implicaciones en el recrudecimiento de la violencia, nuevas amenazas y su transición a nuevas regiones.

- $\mathrm{D}_{3}$. Problemáticas de conflictividad territorial: Estas problemáticas se han generado en diferentes periodos de tiempo desde finales del siglo XIX hasta la violencia contemporánea, que continúa con una marcada brecha territorial y la debilidad de las instituciones, acompañadas de violencia estructural e influencia de los cultivos ilícitos, que durante años han acentuado la intensidad y longevidad de los conflictos sociales, económicos y culturales en las regiones (Ríos \& González, 2021). Además, las dificultades del Estado para implementar los acuerdos de paz y la presencia de una "violencia redefinida sigue siendo una de las urgencias irresolutas para afrontar en los próximos años” (Ríos-Sierra, 2020, p. 158).

- $\quad \mathrm{D}_{4}$. Influencia de la educación superior: Los niveles de desempeño académico en la educación han sido afectados por el conflicto armado, lo que podría in- 
fluenciar el talento humano y la prosperidad de la sociedad en el largo plazo (Munévar et al., 2019). Además, este rezago tiene efectos directos en el riesgo e inseguridad para toda la comunidad (Schuck, 2017). Al respecto, la universidad posee una responsabilidad como institución social y un rol activo en la construcción de una cultura de paz en el país (Flores et al., 2019), por lo cual se deben diseñar metodologías desde este ámbito que integren las visiones individuales y colectivas de los grupos sociales para alcanzar una paz sostenible y duradera (Peña et al., 2020).

- $\mathrm{D}_{5}$. Solución al problema de las drogas ilícitas: Este es un factor transcendental del Acuerdo de Paz para reducir el negocio cocalero y la violencia vinculada a este. Junto con la reforma rural integral, constituye el segundo eje que contribuye a la construcción de paz, y que ha tenido un débil nivel de implementación (Ríos \& González, 2021). Así mismo, el Estado elaboró una política para reducir el consumo de sustancias psicoactivas; reducir la disponibilidad de drogas en mercados internos y externos; desarticular y afectar las estructuras, economías y rentas criminales; tranformar el territorio, y transitar a las economías licitas (Ministerio de Justicia, 2018).

- $\mathrm{D}_{6}$. Reforma rural integral: Las políticas de orden económico y social no han favorecido el desarrollo agrícola de los territorios rurales, han tenido una asignación presupuestal reducida y han generado inequidad en el campo (Junguito et al., 2017); como alternativa a esta problemática, se requiere una reforma agraria profunda que democratice la tierra y erradique la desigualdad, que ofrezca financiación de largo plazo, asistencia técnica y estrategias de participación en el mercado (Matías, 2021).

\section{Conflicto armado, justicia transicional y posconflicto}

El conflicto armado en Colombia se ha analizado ampliamente en las últimas décadas por diferentes expertos e investigaciones, que dan explicaciones desde perspectivas políticas, sociales, culturales y económicas (Zubiría, 2015; Pizarro, 2015; Giraldo, 2015; Torrijos, 2015). Díaz y Sánchez (2004) definen el conflicto armado como los enfrentamientos entre grupos rebeldes, insurgentes e irregulares y el Estado; además, para Giraldo (2015), Pizarro (2015) y Torrijos (2015), es prolongado y complejo; sin embargo, Zuluaga (2004, p. 32) sostiene que no es en sentido estricto una guerra.

La justicia transicional se entiende como el conjunto de mecanismos y herramientas que permiten hacer frente a un legado de graves y masivas violaciones de derechos que implica la necesidad de integrar elementos para garantizar la verdad, la justicia, la reparación y las garantías de no repetición. Como precisa Rincón (2010), la justicia transicional responde a una concepción de justicia vinculada a momentos de transición política —-bien sea de una dictadura hacia la democracia o de un conflicto armado o una guerra hacia 
la paz-, que busca lidiar con un pasado grave de violaciones a los derechos humanos enfrentando los crímenes cometidos bajo regímenes represores o durante un conflicto armado.

Por su parte, el posconflicto tiene diversas acepciones. Inicia después de la firma de un acuerdo de paz, pero no como una etapa que termina con el conflicto, sino como aquella que da inicio a la búsqueda de la paz duradera y estable en un horizonte de tiempo, el periodo en que inicia el cese de hostilidades entre las partes previamente enfrentadas (Rettberg, 2003). Es importante distinguir los conceptos de posacuerdo y posconflicto. El primero hace referencia al periodo posterior a la firma de un acuerdo, que configura nuevas políticas para finalizar las situaciones conflictivas con el grupo insurgente en el corto y mediano plazo; el segundo, como se mencionó, inicia con las políticas del posacuerdo y se orienta hacia la construcción de paz desde una perspectiva de largo plazo (Cepeda, 2016). Ahora bien, la construcción de paz se define como el fortalecimiento y la consolidación de la paz para evitar una recaída en el conflicto.

\section{Construcción de paz en Colombia}

El conflicto armado vivido en Colombia por más de cinco décadas ha dejado "impactos y afectaciones atroces sobre las víctimas, familias, organizaciones, entidades públicas y en general el conjunto de la sociedad colombiana" (Centro Nacional de Memoria Histórica [CNMH], 2013, p. 259). Esto se evidencia en el Registro Único de Víctimas de la Unidad para la Atención y Reparación Integral a las Víctimas (s. f.), que, a diciembre de 2021, registra 9218796 personas afectadas por uno de los hechos victimizantes (actos terroristas, amenazas, delitos contra la libertad e integridad sexual, desplazamiento forzado, homicidios, desaparición forzada, secuestro, abandono o despojo forzado de bienes, lesiones personales, entre otros). Esto evidencia la imperiosa necesidad de una construcción de paz que proporcione las garantías de verdad, justicia, reparación y no repetición.

La construcción de paz busca crear un conjunto de actitudes, planteamientos, medidas y procesos orientados a la transformación de los conflictos violentos en relaciones y estructuras más inclusivas y sostenibles. En este sentido, Grasa y Mateos (2014) sostienen que para ello hacen falta todos los actores de la vida social: administraciones e instituciones de diferentes niveles (nacionales, departamentales, locales), academia, sociedad civil y actores comunitarios diversos, incluyendo pueblos originarios y afrodescendientes, empresarios, entre otros. El grado de incidencia está sujeto a la determinación de los sistemas políticos e institucionales, pero también a la capacidad de acción colectiva y a las diversas dinámicas sociales.

Por otro lado, conducir un proceso de posconflicto requiere integrar la paz entre los diferentes actores, lo que implica enfrentar los múltiples desafíos de la construcción de paz. En sentido estratégico, conlleva ocuparse activamente de tres R: resolver las incompatibilidades que originaron la violencia; reconstruir el daño material e inmaterial causado, y 
reconciliar el derecho a la verdad, la justicia, las reparaciones y la garantía de no repetición (Grasa \& Mateos, 2014). Dichos retos se conocen como transformación de los conflictos o construcción de paz estratégica. Por lo tanto, el contenido y el alcance de la construcción de paz dependen de la realidad socioambiental y requieren un análisis interdisciplinario que integre las condiciones estructurales, culturales y relacionales que nutren la violencia en cada contexto (Wright, 2004).

Los procesos de paz en Colombia marcan los límites de las distintas apuestas por una paz estable y extendida en diferentes ámbitos de la vida cotidiana. En este sentido, el objeto de una negociación como salida de la confrontación implica la necesidad de que nuevas fuerzas sociales participen, no solo en la implementación de eventuales acuerdos, sino en el diseño de convenios y de las dimensiones sociales donde se deberían producir transformaciones, sobre la base de acuerdos políticos plurales que mantengan abierta la posibilidad de reformas durante un tiempo prolongado.

\section{Metodología}

Se aplicó una metodología de enfoque mixto que interrelaciona los aspectos más importantes del método cualitativo y el cuantitativo para mejorar la comprensión de los resultados. Se trata de una investigación descriptiva que utilizó la herramienta prospectiva de matriz de impacto cruzado (SMIC), que permite crear imágenes futuras sobre temas de interés y desarrollo regional, mediante la interrelación de elementos cualitativos y cuantitativos para lograr un análisis de alta consistencia (Zahradnícková \& Vacík, 2014), con múltiples visiones estructuradas del futuro (Phadnis, 2012).

El análisis de datos se realizó con el aplicativo Smic-Prob Expert del laboratorio Lipsor, con el fin de modelar los datos construidos con eventos prospectivos definidos para formular escenarios posibles. Este análisis se alimentó con las probabilidades emitidas por un equipo de actores del desarrollo a través de encuestas (SMIC) para seleccionar las alternativas posibles teniendo en cuenta la probabilidad de realización (Castro, 2019).

La Figura 1 muestra la estructura metodológica de dos etapas y siete fases desarrolladas mediante la aplicación del método de escenarios propuesto por el modelo de Godet (1993):

- Fase 1. Se realizó la selección del tema. A partir de una amplia revisión del estado del arte se identificaron las dimensiones y eventos de futuro sobre la construcción de paz en el Caquetá.

- Fase 2. Se seleccionaron expertos representantes de los actores del desarrollo regional del Caquetá que influencian la construcción de un proceso de paz desde cuatro sectores: saber (universidades, centro de investigación), poder (Estado), sector productivo (gremios) y comunidad. Los actores fueron elegidos mediante un muestreo no probabilístico por conveniencia, bajo el criterio de amplia 
experiencia en el desarrollo del sector y con capacidad de modificarlo por su rol en desempeño laboral o en conocimiento.

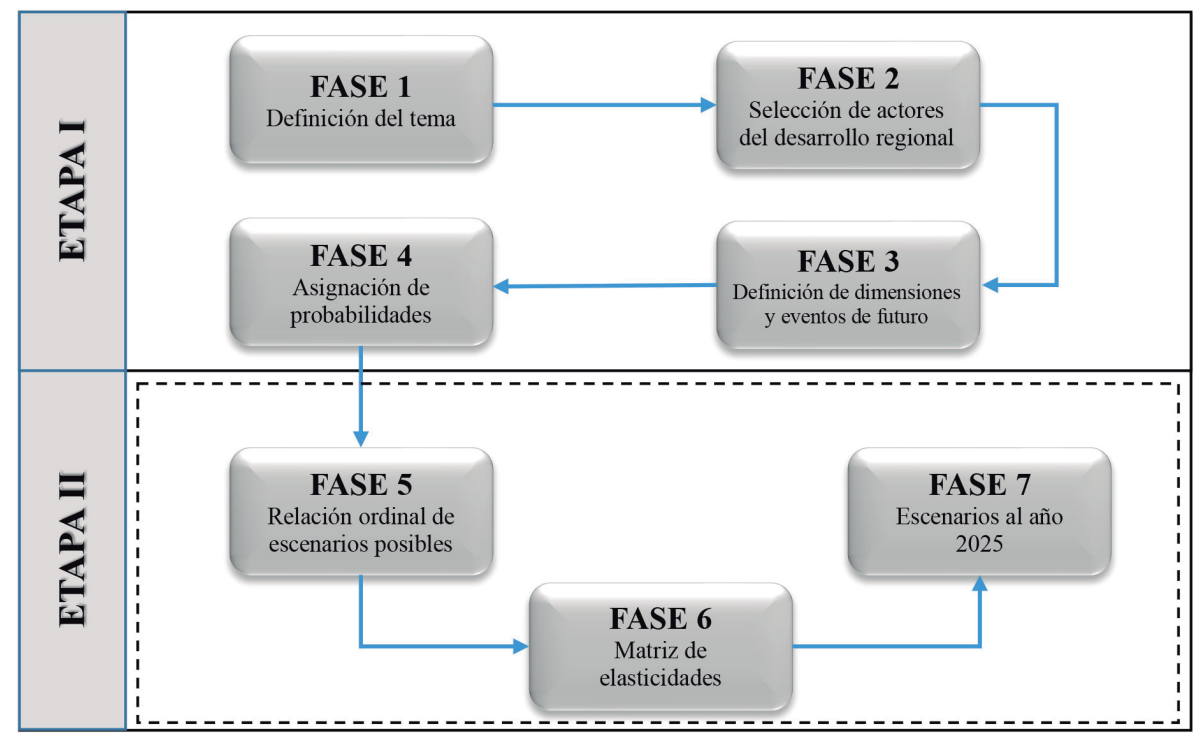

Figura 1. Fases del estudio.

Fuente: Elaboración propia

- Fase 3. Se definieron y validaron las seis dimensiones mencionadas para la construcción de paz en el Caquetá con su respectivo evento de futuro al año 2025: 1) fortalecimiento de capacidades institucionales y de la sociedad civil; 2) víctimas del conflicto; 3) problemáticas de conflictividad territorial; 4) influencia de la educación superior; 5) solución al problema de las drogas ilícitas, y 6) reforma rural integral.

- Fase 4. Los expertos fueron indagados con un instrumento de recolección de información compuesto por 6 enunciados sobre los eventos de futuro con probabilidades simples $(\mathrm{P}(i)$, probabilidad de que $i$ se realice en 2025) sobre las dimensiones que influyen en la construcción de paz en el Caquetá; 30 enunciados de probabilidades condicionadas positivas $(+=\mathrm{P}(i / j))$ (probabilidad de $i$, si se realiza $j)$, y 30 probabilidades condicionadas negativas $(-=\mathrm{P}(i /-j)$, probabilidad de $i$, si no se realiza $j$ ).

De acuerdo con Castro (2019), la etapa 2 incluye las fases 5, 6 y 7, desarrolladas a través del software Smic-Pro Expert y el análisis de datos, que permitió obtener una relación ordinal de escenarios posibles ordenados del más probable al menos probable. Cada escenario muestra la posición de cada evento de futuro codificada de forma binaria, donde 
1 indica ocurrencia y 0 indica no ocurrencia (fase 5); la matriz de elasticidades en términos de probabilidades de las relaciones de influencia/dependencia entre los eventos (fase 6), y el diseño de escenarios al ańo 2025 (fase 7).

\section{Resultados}

De acuerdo con la estructura metodológica, se presentan los resultados de cada una de las fases desarrolladas según el método de Godet (1993). Las fases 1 y 2 focalizaron el estudio y definieron los actores del desarrollo regional; la fase 3 identificó las dimensiones de la investigación $\left(\mathrm{D}_{1}\right.$ a $\left.\mathrm{D}_{6}\right)$ previamente validadas con análisis estadístico y formuló los eventos de futuro $\left(\mathrm{E}_{1}\right.$ a $\left.\mathrm{E}_{6}\right)$ proyectados al año 2025 (Tabla 1).

Tabla 1. Dimensiones para la construcción de paz y eventos de futuro

\begin{tabular}{|c|c|c|}
\hline Dimensiones $\left(\mathrm{D}_{\mathrm{j}}\right)$ & $\begin{array}{c}\mathrm{D}\left({ }_{\mathrm{j}}\right) \\
\text { Abreviado }\end{array}$ & Evento de futuro $\left(\mathrm{E}_{\mathrm{j}}\right)$ \\
\hline $\begin{array}{l}\mathrm{D}_{1} \text {. Fortalecimiento de capaci- } \\
\text { dades institucionales y de la } \\
\text { sociedad civil }\end{array}$ & Capacidad & $\begin{array}{l}\mathrm{E}_{1} \cdot \text { ¿Cuál es la probabilidad de consolidar una } \\
\text { construcción de paz, en un horizonte hacia el año } \\
2025 \text {, si se genera una autonomía administrativa } \\
\text { y financiera en el fortalecimiento de las capaci- } \\
\text { dades institucionales? }\end{array}$ \\
\hline $\mathrm{D}_{2}$. Víctimas del conflicto & Víctimas & $\begin{array}{l}\mathrm{E}_{2} \cdot \text { ¿Qué probabilidad se tiene de lograr un ver- } \\
\text { dadero perdón por las víctimas, si se lograr una } \\
\text { verdad sobre los crímenes y la reparación por el } \\
\text { daño causado? }\end{array}$ \\
\hline $\begin{array}{l}\mathrm{D}_{3} \text {. Problemáticas de conflictiv- } \\
\text { idad territorial }\end{array}$ & Conflictiv & $\begin{array}{l}\mathrm{E}_{3} \text {. ¿Qué probabilidad existe de disminuir las } \\
\text { problemáticas de conflictividad territorial aso- } \\
\text { ciada al proceso de construcción de paz, si no se } \\
\text { logra disminuir las tensiones económicas, legales } \\
\text { y sociales, y se pierde la participación de las cor- } \\
\text { poraciones públicas del país? }\end{array}$ \\
\hline $\begin{array}{l}\mathrm{D}_{4} \text {. Influencia de la educación } \\
\text { superior }\end{array}$ & EduSuperi & $\begin{array}{l}\mathrm{E}_{4} \cdot \text { ¿Cuál es la probabilidad de que se incremente } \\
\text { la participación activa de las instituciones de ed- } \\
\text { ucación superior, con programas transformadores } \\
\text { para la población desmovilizada en un horizonte } \\
\text { del año } 2025 \text { ? }\end{array}$ \\
\hline $\begin{array}{l}\mathrm{D}_{5} \text {. Solución al problema de las } \\
\text { drogas ilícitas }\end{array}$ & DrogasIlí & $\begin{array}{l}\mathrm{E}_{5} \text { ¿ ¿Cuál es la probabilidad de disminuir } 10000 \\
\text { hectáreas de cultivos ilícitos por año en un hori- } \\
\text { zonte al } 2025 \text { en la región, al ser uno de los flage- } \\
\text { los que financia el conflicto armado? }\end{array}$ \\
\hline $\mathrm{D}_{6}$. Reforma rural integral & Re.Rural & $\begin{array}{l}\mathrm{E}_{6 .} \text { ¿Qué probabilidad se tiene de lograr una } \\
\text { reforma rural integral en Colombia, si no se logra } \\
\text { un plan de inversión y convivencia en el desarrol- } \\
\text { lo sostenible de las comunidades vulnerables por } \\
\text { el conflicto? }\end{array}$ \\
\hline
\end{tabular}

Fuente: Peña (2020) 
En la fase 4, los representantes de los actores del desarrollo (comunidad, sector productivo, poder, saber) asignaron la probabilidad de ocurrencia de cada evento futuro $\left(\mathrm{E}_{\mathrm{j}}\right)$ en un periodo de tiempo determinado. La Tabla 2 muestra el nivel de influencia de los actores sobre los eventos futuros de acuerdo con sus calificaciones, ya que estas reflejan las probabilidades simples asignadas por ellos, quienes serán los responsables en el tiempo de lograr la construcción de paz estable y duradera. Los resultados ubicaron como "muy fuerte", en primer renglón, a la dimensión $\mathrm{D}_{1}$ (fortalecimiento de capacidades institucionales y de la sociedad civil) y en segundo renglón la $\mathrm{D}_{5}$ (solución al problema de las drogas ilícitas). En tercer y cuarto lugar se encuentran con una calificación de "moderado" la dimensión $\mathrm{D}_{3}$ (problemáticas de conflictividad territorial) y la $\mathrm{D}_{4}$ (influencia de la educación superior).

Tabla 2. Probabilidad simple (P) de ocurrencia de cada dimensión en el futuro

\begin{tabular}{ccccc}
\hline $\begin{array}{c}\text { Actores } \\
\text { Dimensiones }\end{array}$ & $\begin{array}{c}\text { Comunidad } \\
\%\end{array}$ & $\begin{array}{c}\text { Productivo } \\
\%\end{array}$ & $\begin{array}{c}\text { Poder } \\
\%\end{array}$ & $\begin{array}{c}\text { Saber } \\
\%\end{array}$ \\
\hline Capacidad & 100 & 50 & 50 & 60 \\
Víctimas & 20 & 5 & 30 & 30 \\
Conflictividad & 10 & 50 & 70 & 10 \\
Educación superior & 50 & 30 & 30 & 40 \\
Drogas ilícitas & 60 & 20 & 75 & 20 \\
Reforma rural & 10 & 40 & 10 & 5 \\
\hline
\end{tabular}

Nota: Criterio de análisis: muy fuerte (90\%), fuerte (80\%), moderado (70\%), débil (60\%), muy débil $(50 \%)$ y duda $(<50 \%)$.

Fuente: Peña (2020)

En la fase 5, con base en las calificaciones de los actores, se hicieron modelaciones en el Smic-Prob Expert. A continuación se presenta la valoración mediante la cual los expertos estiman el impacto $\mathrm{P}(\mathrm{i} / \mathrm{j})$, donde se obtienen las diferentes relaciones de comparación. Se hace un ajuste de la probabilidad simple que se identifica como $\mathrm{P}^{*}$, el cual permite establecer el siguiente criterio de análisis: muy fuerte $(90 \%)$, fuerte $(80 \%)$, moderado (70\%), débil (60\%), muy débil (50\%) y duda (<50\%), como se observa en la Tabla 3 .

En esta fase los actores registran una calificación que se ha llamado P, cuya validación en el Smic-Prob Expert se ajusta a P*. Es en las probabilidades netas ajustadas donde se identifica el $\mathrm{E}_{1}$ como muy débil y los demás con un criterio de duda. Esta situación es un indicador de alcance ambicioso de los eventos si son abordados de manera separada e independiente, sin generar una sinergia. 
Tabla 3. Probabilidad simple ajustada $\left(\mathrm{P}^{*}\right)$ por el conjunto de expertos

\begin{tabular}{|c|c|c|c|}
\hline Evento al año 2025 & $\mathbf{P}$ & $\mathbf{P}^{*}$ & $\begin{array}{l}\text { Criterio } \\
\text { tendencial }\end{array}$ \\
\hline $\begin{array}{l}E_{1} \cdot \text { ¿Cuál es la probabilidad de consolidar una } \\
\text { construcción de paz, en un horizonte hacia el año } \\
2025 \text {, si se genera una autonomía administrativa y } \\
\text { financiera en el fortalecimiento de las capacidades } \\
\text { institucionales? }\end{array}$ & 0,650 & 0,441 & Muy débil \\
\hline $\begin{array}{l}\mathrm{E}_{2} \cdot \text { ¿Qué probabilidad se tiene de lograr un verdade- } \\
\text { ro perdón por las víctimas, si se lograr una verdad } \\
\text { sobre los crímenes y la reparación por el daño cau- } \\
\text { sado? }\end{array}$ & 0,213 & 0,28 & Duda \\
\hline $\begin{array}{l}\mathrm{E}_{3} \cdot \text { ¿Qué probabilidad existe de disminuir las prob- } \\
\text { lemáticas de conflictividad territorial asociada al } \\
\text { proceso de construcción de paz, si no se logra dis- } \\
\text { minuir las tensiones económicas, legales y sociales, } \\
\text { y se pierde la participación de las corporaciones } \\
\text { públicas del país? }\end{array}$ & 0,350 & 0,399 & Duda \\
\hline $\begin{array}{l}\mathrm{E}_{4} \cdot \text { ¿Cuál es la probabilidad de que se incremente } \\
\text { la participación activa de las instituciones de ed- } \\
\text { ucación superior, con programas transformadores } \\
\text { para la población desmovilizada en un horizonte del } \\
\text { año } 2025 \text { ? }\end{array}$ & 0,375 & 0,321 & Duda \\
\hline $\begin{array}{l}\mathrm{E}_{5} \cdot \text { ¿Cuál es la probabilidad de disminuir } 10000 \\
\text { hectáreas de cultivos ilícitos por año en un horizon- } \\
\text { te al } 2025 \text { en la región, al ser uno de los flagelos que } \\
\text { financia el conflicto armado? }\end{array}$ & 0,44 & 0,403 & Duda \\
\hline $\begin{array}{l}\mathrm{E}_{6} \cdot \text { ¿Qué probabilidad se tiene de lograr una reforma } \\
\text { rural integral en Colombia, si no se logra un plan de } \\
\text { inversión y convivencia en el desarrollo sostenible de } \\
\text { las comunidades vulnerables por el conflicto? }\end{array}$ & 0,163 & 0,359 & Duda \\
\hline
\end{tabular}

Fuente: Peña (2020)

La fase 6 muestra la selección aleatoria de los diferentes escenarios: si el $\mathrm{E}_{\mathrm{n}}$ seleccionado no ocurrió, las probabilidades iniciales no cambian; por el contrario, si el evento ocurre, las probabilidades iniciales se ajustan con el algoritmo utilizado. La Tabla 4 presenta las probabilidades de los escenarios acumuladas y ordenadas con los resultados del Smic-Prob Expert (Figura 2). Se validaron las calificaciones de los actores, lo que identificó las dimensiones para la construcción de paz y sus variables. Con las probabilidades acumuladas hasta un $80 \%$ (para este estudio llegan a 79,9\%), se presenta una codificación binaria ( 1 o 0 ) de los seis eventos planteados, donde se identifican diecinueve escenarios de futuro. 
Tabla 4. Probabilidades acumuladas de los escenarios de futuro (actores del desarrollo)

\begin{tabular}{ccccccc}
\hline Actores & $\begin{array}{c}\text { Saber } \\
\%\end{array}$ & $\begin{array}{c}\text { Poder } \\
\%\end{array}$ & $\begin{array}{c}\text { Productivo } \\
\%\end{array}$ & $\begin{array}{c}\text { Comunidad } \\
\%\end{array}$ & $\begin{array}{c}\text { Promedio } \\
\text { actores }\end{array}$ & $\begin{array}{c}\text { Acumulado } \\
\%\end{array}$ \\
\hline $\mathbf{6} \mathbf{- 0 0 0 0 0 0}$ & 0,535 & 0,143 & 0,001 & 0,493 & 0,293 & 0,293 \\
$\mathbf{6 3}-\mathbf{0 0 0 0 0 1}$ & 0,057 & 0,028 & 0,127 & 0 & 0,053 & 0,346 \\
$\mathbf{6 2}-\mathbf{0 0 0 0 1 0}$ & 0 & 0 & 0,192 & 0 & 0,048 & 0,394 \\
$\mathbf{0 2}-\mathbf{1 1 1 1 1 0}$ & 0,062 & 0,047 & 0,04 & 0 & 0,038 & 0,432 \\
$\mathbf{0 3}-\mathbf{1 1 1 1 0 1}$ & 0,021 & 0 & 0,118 & 0 & 0,035 & 0,467 \\
$\mathbf{0 9}-\mathbf{1 1 0 1 1 1}$ & 0,042 & 0 & 0 & 0,099 & 0,035 & 0,502 \\
$\mathbf{2 1}-\mathbf{1 0 1 0 1 1}$ & 0 & 0,129 & 0 & 0,01 & 0,035 & 0,537 \\
$\mathbf{5 6}-\mathbf{0 0 1 0 0 0}$ & 0,025 & 0,112 & 0 & 0 & 0,034 & 0,571 \\
$\mathbf{1 7}-\mathbf{1 0 1 1 1 1}$ & 0,02 & 0,01 & 0 & 0,088 & 0,029 & 0,6 \\
$\mathbf{1 8}-\mathbf{1 0 1 1 1 0}$ & 0 & 0,084 & 0 & 0,018 & 0,026 & 0,626 \\
$\mathbf{3 2}-\mathbf{1 0 0 0 0 0}$ & 0 & 0,095 & 0 & 0 & 0,024 & 0,65 \\
$\mathbf{0 1}-\mathbf{1 1 1 1 1 1}$ & 0,041 & 0 & 0 & 0,053 & 0,023 & 0,673 \\
$\mathbf{0 5}-\mathbf{1 1 1 0 1 1}$ & 0 & 0,072 & 0 & 0,02 & 0,023 & 0,696 \\
$\mathbf{0 6}-\mathbf{1 1 1 0 1 0}$ & 0 & 0,038 & 0 & 0,043 & 0,02 & 0,716 \\
$\mathbf{2 5}-\mathbf{1 0 0 1 1 1}$ & 0,009 & 0 & 0 & 0,065 & 0,019 & 0,735 \\
$\mathbf{1 9}-\mathbf{1 0 1 1 0 1}$ & 0,03 & 0 & 0,036 & 0 & 0,017 & 0,752 \\
$\mathbf{2 4}-\mathbf{1 0 1 0 0 0}$ & 0 & 0 & 0,066 & 0 & 0,016 & 0,768 \\
$\mathbf{6 0}-\mathbf{0 0 0 1 0 0}$ & 0 & 0,064 & 0 & 0 & 0,016 & 0,784 \\
$\mathbf{1 0}-\mathbf{1 1 0 1 1 0}$ & 0 & 0 & 0 & 0,06 & 0,015 & 0,799 \\
\hline
\end{tabular}

Nota: El acumulado muestra el número de escenarios de ocurrencia en el futuro hasta llegar al 0,799.

Fuente: Lipsor EPITA Smic-Prob Expert (Peña, 2020)

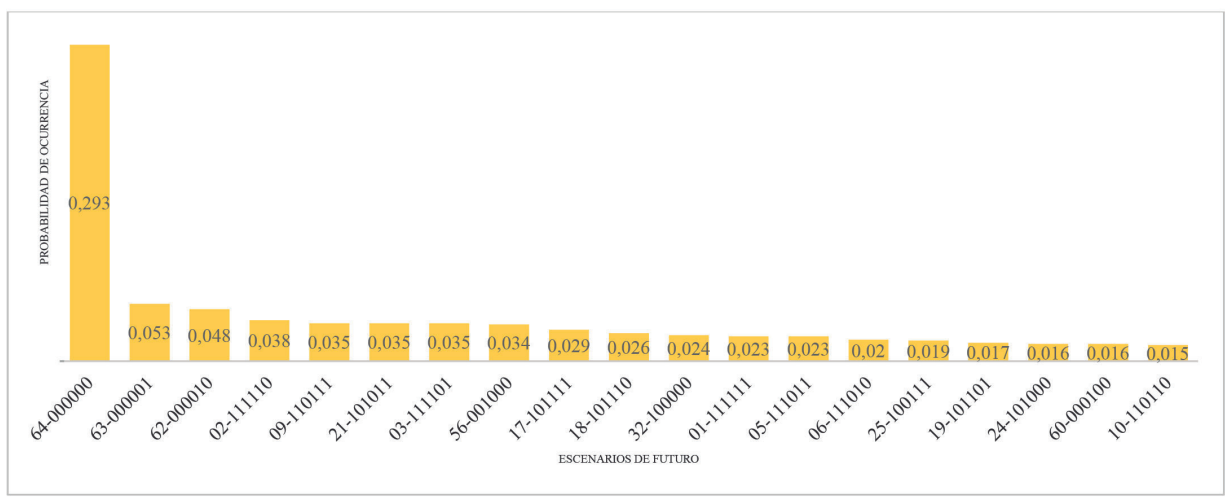

Figura 2. Histograma de probabilidades de los escenarios (conjunto de actores). Fuente: Elaboración propia con resultados de Lipsor EPITA Smic-Prob Expert 
Para una aproximación a la ordenación de los escenarios, se parte del análisis de sensibilidad (Tabla 5). Este análisis informa cuál es la elasticidad de ocurrencia de los eventos entre sí; en otras palabras, en qué medida, cuando aumenta la probabilidad de ocurrencia de cada evento, se espera que aumente la probabilidad de ocurrencia de los demás relacionados. Así, el análisis de sensibilidad indica cuáles son los eventos que hay que favorecer o impedir para que el sistema se desarrolle en el sentido deseado. Aunque estas elasticidades pueden ser calculadas por simulación — haciendo girar varias veces el modelo de relaciones entre las probabilidades para un gran número de actores-, es también posible medir el impacto de un acontecimiento sobre otro a través de la comparación de desplazamientos de los histogramas de $\mathrm{P}(\mathrm{i}), \mathrm{P}(\mathrm{i} / \mathrm{j})$ y $\mathrm{P}(\mathrm{i} /-\mathrm{j})$.

Tabla 5. Matriz de elasticidad

\begin{tabular}{lccccccc}
\hline & $\begin{array}{c}\text { Capaci- } \\
\text { dades }\end{array}$ & Víctimas & $\begin{array}{c}\text { Conflic- } \\
\text { tivid }\end{array}$ & $\begin{array}{c}\text { EduSupe- } \\
\text { rior }\end{array}$ & DrogasIlí & Re.Rural & $\begin{array}{c}\text { Suma } \\
\text { absoluta }\end{array}$ \\
\hline 1: Capacidades & 1 & 0,302 & 0,125 & 0,222 & 0,149 & 0,109 & 0,907 \\
2: Víctimas & 0,05 & 1 & 0,026 & 0,049 & 0,015 & 0,004 & 0,144 \\
3: Conflictivid & 0,064 & 0,11 & 1 & 0,076 & 0,02 & 0,011 & 0,281 \\
4. EduSuperior & 0,055 & 0,082 & 0,026 & 1 & 0,046 & 0,032 & 0,24 \\
4: Drogasllí & 0,098 & 0,093 & 0,007 & 0,085 & 1 & 0,021 & 0,304 \\
6: Re.Rural & 0,016 & 0,016 & $-0,009$ & 0,052 & $-0,006$ & 1 & 0,099 \\
7: Suma absoluta & 0,284 & 0,602 & 0,193 & 0,483 & 0,236 & 0,177 & - \\
\hline
\end{tabular}

Fuente: Lipsor EPITA Smic-Prob Expert

El coeficiente de elasticidad mide el cambio porcentual de la variable $j$ debido a un cambio unitario en $i$. La Tabla 5 indica que la dimensión 1 presenta la mayor elasticidad $(0,302)$ de ocurrencia para las víctimas, lo que significa que, para consolidar un verdadero perdón por las víctimas y verdad sobre los crímenes y la reparación por el daño causado, se requiere una consolidación del fortalecimiento de capacidades institucionales con la generación de autonomía administrativa y financiera, que permitan una reconciliación y reconstrucción del proceso de paz.

La elasticidad de los eventos se muestra de manera ordenada en el histograma de sensibilidad de influencias (Figura 3), que recapitula las sumas en la línea de influencia, y en la columna de dependencia de la matriz de elasticidad permite tener los eventos más influyentes y más dependientes en la construcción de paz en el Caquetá. Los resultados destacan la $\mathrm{D}_{1}$ y la $\mathrm{D}_{5}$ como los eventos más motrices en cuanto generadores en la construcción de paz. Para la primera (fortalecimiento de capacidades), es indispensable definir los mecanismos de autonomía administrativa y financiera de los organismos o entidades 
descentralizadas de los niveles regional y local para una mayor dinamización; para la segunda (víctimas), se debe combatir el flagelo principal de la financiación de los grupos al margen de la ley para despejar el camino hacia una construcción de paz.

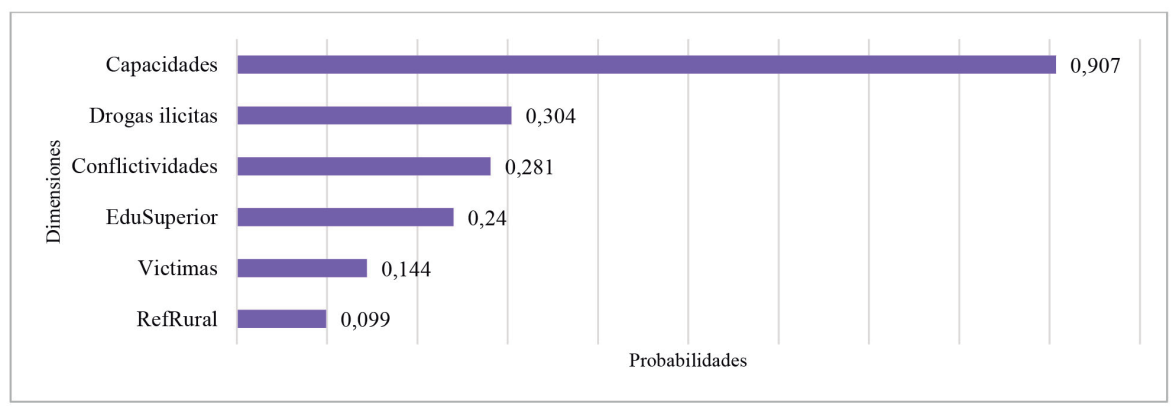

Figura 3. Histograma de sensibilidad de influencia (conjunto de actores). Fuente: Elaboración propia con datos de Lipsor EPITA Smic-Prob Expert

También es necesario conocer la organización de los eventos desde la dependencia, como se aprecia en la Figura 4. $\mathrm{Al}$ respecto, los eventos más representativos son la $\mathrm{D}_{3}$ y la $\mathrm{D}_{4}$, ya que están sujetos a un verdadero cambio en el fortalecimiento de las capacidades de las instituciones descentralizadas del nivel regional y local y al logro de una verdadera reducción de las plantaciones de cultivos ilícitos en el departamento del Caquetá.

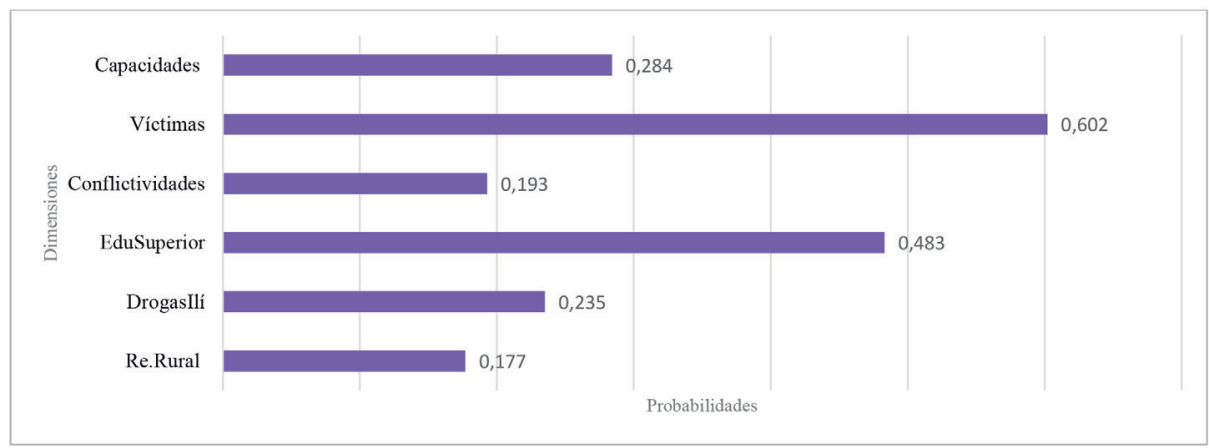

Figura 4. Histograma de sensibilidad de dependencia (conjunto de actores). Fuente: Elaboración propia con datos de Lipsor EPITA Smic-Prob Expert

En la fase 7, el análisis tiene como finalidad presentar los valores extremos de los escenarios. Una vez se calculan las soluciones intermedias de probabilidades, se introduce un criterio de selección y se retiene como solución óptima aquella que corresponda al conjunto de probabilidades de escenarios. De esta forma, el escenario más probable tendrá el valor más elevado posible y será el que corresponde más fielmente a la realidad. Esto refleja lo que la mayoría de los expertos piensan cuando responden al cuestionario Smic- 
Prob Expert, es decir, una imagen final que consideran netamente más probable que las demás (Tabla 6).

Tabla 6. Escenarios para la construcción de paz en el Caquetá 2025

\begin{tabular}{|c|c|c|c|c|}
\hline \multirow{2}{*}{\multicolumn{2}{|c|}{ Escenarios de futuro }} & \multicolumn{2}{|c|}{ Probabilidad } & \multirow{2}{*}{ Descripción } \\
\hline & & Individual & Suma & \\
\hline Pesimista & 64-000000 & $43,2 \%$ & $43,2 \%$ & $\mathbf{E}_{64}$ Ninguna dimensión se logra. \\
\hline Apuesta & $1-111111$ & $15,3 \%$ & $15,3 \%$ & $\mathbf{E}_{1}$. Se logran todas las dimensiones. \\
\hline \multirow{3}{*}{$\begin{array}{l}\text { Optimista } \\
\text { tendencial }\end{array}$} & $2-111110$ & $13,4 \%$ & \multirow{3}{*}{$39,4 \%$} & $\begin{array}{l}\mathrm{E}_{2} \text {. No se logra la dimensión } \mathrm{D}_{6} \text {, pero } \\
\text { se logran las demás. }\end{array}$ \\
\hline & 63-000001 & $13,3 \%$ & & $\begin{array}{l}\mathbf{E}_{63} \text {. No se logran las dimensiones } \mathrm{D}_{1} \text {, } \\
\mathrm{D}_{2}, \mathrm{D}_{3}, \mathrm{D}_{4} \text { y } \mathrm{D}_{5} \text {, pero se logra la } \mathrm{D}_{6} \\
\text { en el futuro. }\end{array}$ \\
\hline & 56-001000 & $12,7 \%$ & & $\begin{array}{l}\mathbf{E}_{56} \text {. No se logran las dimensiones } \mathrm{D}_{1} \text {, } \\
\mathrm{D}_{2}, \mathrm{D}_{4}, \mathrm{D}_{5} \text { y } \mathrm{D}_{6} \text {, pero se logra la } \mathrm{D}_{3} \\
\text { en el futuro. }\end{array}$ \\
\hline \multirow{3}{*}{ Negativo } & $62-000010$ & $12 \%$ & \multirow{3}{*}{$33,95 \%$} & $\begin{array}{l}\mathbf{E}_{62} \text {. No se logran las dimensiones } \mathrm{D}_{1} \text {, } \\
\mathrm{D}_{2}, \mathrm{D}_{3}, \mathrm{D}_{4} \text { y } \mathrm{D}_{6} \text {, pero se logra la } \mathrm{D}_{5} \\
\text { en el futuro. }\end{array}$ \\
\hline & 09-110111 & $11 \%$ & & $\begin{array}{l}\mathbf{E}_{09} \text {. No se logra la dimensión } \mathrm{D}_{3} \text {, } \\
\text { pero se logran las demás en el futuro. }\end{array}$ \\
\hline & 03-111101 & $10,9 \%$ & & $\begin{array}{l}\mathbf{E}_{03} \text {. No se logra la } \mathrm{D}_{5} \text {, pero se logran } \\
\text { las demás en el futuro. }\end{array}$ \\
\hline
\end{tabular}

Fuente: Peña (2020)

El escenario apuesta se manifiesta como el resultado de las interacciones entre los diferentes escenarios en la dinámica de las soluciones contrastadas, es decir que integra las probabilidades de los diferentes escenarios en busca de maximizar el escenario más probable.

Como se puede observar, la Tabla 6 presenta escenarios negativos y positivos: el primero $\left(\mathrm{E}_{64}-000000\right)$ corresponde a una postura negativa y tiene una mayor probabilidad de ocurrencia (43,2\%). Este escenario pesimista es un fracaso en el tiempo que diluye la autonomía administrativa y financiera en las instituciones, lo que afecta el desarrollo de sus capacidades. Así mismo, la Justicia Especial para la Paz no logra un verdadero perdón y confesión de los crímenes atroces; se incrementan las conflictividades territoriales; la educación superior continúa en su proceso formativo sin dar respuestas transformadoras a la construcción de paz; hay ineficiencia en la erradicación de los cultivos ilícitos en la región y el país, y, para completar, hay lentitud en los procesos de restitución de tierras y de recuperación de la reforma rural integral. 
El segundo escenario $\left(\mathrm{E}_{1}-111111\right)$, donde todos los eventos se cumplen, aunque tiene una menor probabilidad de ocurrencia $(15,3 \%)$, se convierte en el escenario apuesta para reorientar acciones futuras en la generación de autonomía administrativa y financiera de las capacidades institucionales, así como una apertura mental y emocional para un verdadero perdón y esclarecimiento de los crímenes. La educación superior presenta programas transformadores a los desmovilizados en las zonas de normalización; hay atención a las conflictividades territoriales y sostenibilidad de la participación política; se optimizan los indicadores en la erradicación de los cultivos ilícitos, y hay recuperación y restitución de tierras a los desplazados y afectados por el conflicto armado.

\section{Discusión}

La implementación de herramientas prospectivas como el Smic-Prob Expert es fundamental para los estudios en estas disciplinas porque permite identificar los direccionadores estratégicos que orientarán las acciones en el futuro desde lo político, lo cultural, lo social y lo económico, buscando generar sinergia entre los actores del conflicto. Al respecto, León-Mirabent et al. (2020) concluyen que estas técnicas de construcción de escenarios son viables y efectivas para identificar visiones compartidas en el largo plazo, lo cual permite tomar decisiones en el presente frente a las condiciones internacionales, nacionales y locales que afectan a la sociedad.

En esta investigación, las dimensiones identificadas que influencian el desarrollo de la construcción de paz en el Caquetá fueron sometidas a evaluación por los actores del desarrollo en los sectores productivo, del saber, del poder y la comunidad, quienes identificaron una influencia alta del fortalecimiento de las capacidades institucionales y de la sociedad $\left(\mathrm{D}_{1}\right)$ y de la solución al problema de los cultivos ilícitos $\left(\mathrm{D}_{5}\right)$, así como dieron una evaluación media a la conflictividad territorial asociada al proceso de construcción de paz $\left(\mathrm{D}_{3}\right)$ y a la influencia de la educación superior en dicho proceso $\left(\mathrm{D}_{4}\right)$. Al respecto, Kahane (2016) coincide desde su experiencia como asesor de los países en conflicto (entre ellos, Guatemala, Sudán, Sudáfrica, Canadá y Colombia) en que es pertinente la incidencia de los actores del sector empresarial, los intelectuales, el Estado y la sociedad para lograr una verdadera transformación desde el pensamiento y, por ende, desde las acciones que permitan una orientación en el futuro.

Estos resultados fueron confirmados en el análisis de sensibilidad, donde se ratifica el fortalecimiento de capacidades $\left(\mathrm{D}_{1}\right)$ y la solución al problema de los cultivos ilícitos $\left(\mathrm{D}_{5}\right)$ como las dimensiones de mayor motricidad generadora en la construcción de paz; sin embargo, para lograr dicha dinamización se debe conocer las dimensiones desde su dependencia: las víctimas del conflicto $\left(\mathrm{D}_{2}\right)$ y la influencia de la educación superior $\left(\mathrm{D}_{4}\right)$, que están sujetas a un verdadero cambio en las dimensiones de mayor motricidad para lograr una construcción de paz estable y duradera. Frente a las dimensiones dependientes, las víctimas son parte fundamental de la política de Estado en materia de justicia y derechos 
humanos por sus afectaciones del conflicto armado (Guglielmucci, 2017). Así mismo, la Misión de Verificación de la ONU en Colombia (Sandoval, 2017) sostiene que el Estado debe gestar las medidas necesarias que permitan vincular a las comunidades vulnerables en la construcción colectiva de un territorio en paz, para mantener así la confianza en la paz estable y duradera.

Para preservar el desarrollo de cada una de estas dimensiones, no es muy alentador el panorama en la consolidación de una agenda desde la perspectiva de lograr mayores éxitos en la construcción de paz. En este sentido, Grasa (2020) destaca dentro de los factores con mayor impacto en este proceso la confrontación política y social, la consolidación de la polarización y la afectación de la salubridad y la economía por la pandemia. Respecto a este último, hay que resaltar que "las subregiones del país presentan deficiencias en la capacidad asistencial de los centros rurales, con protocolos de seguridad y distanciamiento más severos, y un significativo nivel de contagio también entre el personal sanitario" (Pardo et al., 2020, p. 10). La presencia de estos factores influye en las acciones gubernamentales, con una afectación directa en los procesos electorales democráticos de 2022-2023.

Así, el panorama nacional no es alentador. Las cifras evidencian una reactivación de los grupos armados organizados residuales que tiene fuertes implicaciones en el devenir de la construcción de paz. Al respecto, Caquetá es el quinto departamento con mayor margen de influencia de las acciones delincuenciales de estos grupos (Álvarez et al., 2018). Además, Pirateque (2021) señala que los nuevos escenarios que se tejen a partir de la influencia de grupos disidentes en el país repercuten directamente en la articulación de esquemas de seguridad y defensa nacional que permitan salvaguardar el territorio, específicamente zonas periféricas que suelen ser sensibles y vulnerables ante este tipo de situaciones.

Como se afirmó arriba, esto ha afectado el optimismo en que cada una de estas dimensiones se pueda presentar en el horizonte de tiempo a 2025 con una mayor probabilidad. No obstante, el resultado final de escenarios reconoce la necesidad de enfocar las acciones hacia el escenario $\mathrm{E}_{1}-111111$, con una probabilidad acumulada de 15,3\%, donde se pueden presentar las soluciones contrastadas como el escenario apuesta. Este porcentaje es una oportunidad en el tiempo que debe sostenerse como esperanza de la construcción de paz estable y duradera.

\section{Conclusiones}

Con el resultado de la matriz de soluciones contrastadas del SMIC se estructuró el escenario de futuro en la construcción de paz, donde se presentan escenarios negativos y positivos: el escenario pesimista $\left(\mathrm{E}_{64}-000000\right)$ es una postura negativa con la mayor probabilidad de ocurrencia (43,2\%): en él, estos eventos no saldrían adelante, así que continuaría la inercia económica, social, política y cultural; el escenario apuesta $\left(\mathrm{E}_{1}-111111\right)$ tiene una menor probabilidad de ocurrencia $(15,3 \%)$, pero se identifica como escenario apuesta para reorientar las acciones futuras. 
Pensar en el futuro implica una estructura mental para definir las acciones que conduzcan al futuro desde el presente. Solamente la acción humana puede trascender la decisión para poder construir hacia adelante, y así mitigar el impacto de la incertidumbre. En esto consiste la narrativa del escenario apuesta, con el 15,3\% de probabilidad, pues su viabilidad depende de la atención y diligencia en la acción humana de los actores de desarrollo, quienes consolidan la construcción de paz en el futuro.

Con la metodología del Smic-Prob Expert se pudo corroborar en gran medida que, de las seis dimensiones estudiadas, cuatro son de afectación directa. En este sentido, los actores del desarrollo en el Caquetá deben enfocar sus acciones en la implementación de los escenarios en las dimensiones de mayor influencia para construir la paz, que son el fortalecimiento de capacidades institucionales y la solución del problema de cultivos ilícitos. Así mismo, se resaltan las dimensiones de mayor dependencia identificadas: las víctimas del conflicto y la influencia de la educación superior. Esto no quiere decir que las otras dos dimensiones se pierdan para el análisis, pues aunque quedan con un menor porcentaje de participación, son muy activas e importantes en la construcción de una paz estable y duradera para el Caquetá.

\section{Agradecimientos}

Los autores desean agradecer a la Secretaría de Planeación de la Gobernación del Caquetá, la Oficina de Paz de la Universidad de la Amazonia y demás actores sociales del Departamento de Caquetá (universidades, institutos descentralizados del orden departamental, sector empresarial y clase política) por su apoyo en la realización de este artículo.

\section{Declaración de divulgación}

Los autores declaran que no existe ningún potencial conflicto de interés relacionado con el artículo. Este artículo es resultado del trabajo de investigación doctoral "Diseño de escenarios en la construcción de un proceso de paz en el Caquetá, Colombia”.

\section{Financiamiento}

Los autores no declaran fuente de financiamiento para la realización de este artículo.

\section{Sobre los autores}

Parcival Peña Torres es doctor en gerencia y política educativa. Es docente titular del programa de Administración de Empresas de la Universidad de la Amazonia, Colombia, con trayectoria y experiencia en estudios prospectivos y estratégicos territoriales.

https://orcid.org/0000-0002-1656-7111 - Contacto: pa.pena@udla.edu.co

Claritza Marlés Betancourt es doctora en educación y cultura ambiental. Es docente asociada del programa de Administración de Empresas de la Universidad de la Amazonia, Colombia, con experiencia en estudios prospectivos y gamificación.

https://orcid.org/0000-0002-1314-7517 - Contacto: c.marles@udla.edu.co 
Orlando Valera Alfonso es doctor en ciencias pedagógicas. Es profesor titular de la Universidad de La Habana, Cuba. Es asesor y consultor internacional de la Asociación Internacional de Educación Cognitiva y Psicología (IACEP), Cuba. https://orcid.org/0000-0002-0359-8074 - Contacto: orlandovalera@infomed.sld.cu

\section{Referencias}

Álvarez V., E., Pardo C., D., \& Cajiao V., A. (2018). Trayectorias y dinámicas territoriales de las disidencias de las FARC (Informe 30). Fundación Ideas para la Paz (FIP). https://bit.ly/3DQdUMb

Álvarez-Rodríguez, A. (2017). Acuerdos y construcción de paz en Colombia: retos a la gobernabilidad y la cultura de paz. Revista de Trabajo Social e Intervención Social, 24, 13-45. https://doi.org/10.25100/ prts.v0i24.5872

Arias, D. P. (2020). La implementación del acuerdo de paz y la transformación del conflicto armado en Colombia. Revista Cientifica General José María Córdova, 18(31), 565-584. http://dx.doi. org/10.21830/19006586.621

Berger, G. (1964). Phénoménologie du temps et prospective. Presses Universitaires de France.

Blyth, M. (2005, marzo). Learning from the future through scenario planning (Scenario Planning). https:// bit.ly/3IN7qS2

Brabandere, L., \& Iny, A. (2010). Scenarios and creativity: thinking in new boxes. Technological Forecasting and Social Change, 77(9), 1506-1512. https://doi.org/10.1016/j.techfore.2010.07.003

Bradfield, R. (2004). Origins and evolution of scenario techniques in the context of business. University of Strathclyde Graduate School of Business.

Bradfield, R., Wright, G., Burt, G., Cairns, G., \& Van der Heijden, K. (2005). The origins and evolution of scenario techniques in long range business planning. Futures, 37(1), 795-812. https://doi.org/10.1016/j. futures.2005.01.003

Castro Gallo, E. (2019). Escenarios prospectivos para el desarrollo integral del Purús al 2040 [tesis de maestría, Universidad Mayor de San Marcos, Lima, Perú]. https://hdl.handle.net/20.500.12672/11721

Centro Nacional de Memoria Histórica (CNMH). (2013, agosto). ;Basta ya! Colombia: Memorias de guerra y dignidad (informe general, Grupo de Memoria Histórica). https://bit.ly/31TbrTO

Cepeda Jiménez, J. A. (2016). El posacuerdo en Colombia y los nuevos retos de la seguridad. Cuadernos de Estrategia, 181, 195-224. https://bit.ly/31JqOi9

Concheiro, A., \& Medina, J. (Eds.). (2013). Eleonora Masini: alma de los estudios de futuro. Fundación Javier Barros Sierra. https://bit.ly/3IJuQHO

Chermack, T. (2004). Improving decision-making with scenario planning. Futures, 36(3), 295-309. https:// doi.org/10.1016/S0016-3287(03)00156-3

Dator, J. (2019). Futures studies as applied knowledge. In Jim Dator: a noticer in time (pp. 7-16). Springer.

Durance, P., \& Godet, M. (2010). Scenario building: Uses and abuses. Technological forecasting and Social Change, 77(9), 1488-1492. https://doi.org/10.1016/j.techfore.2010.06.007

Flores, J. F., Ramos, I. G., \& Almazán, J. A. (2019). Construcción de una cultura de paz desde el ámbito universitario: actores e instituciones. El caso Colombia. Revista de Cultura de Paz, 3, 317-333. https:// bit.ly/3oKlCTI

Gauna, D., Patrouilleau, M., Schuff, P., \& González, L. (2020). Profundización en tres métodos y técnicas: Escenarios, Backcasting y Delphi. Instituto Nacional de Tecnología Agropecuaria; Procadis. https:// bit.ly/3oJWMmR 
Giraldo, J. (2015). Aportes sobre el origen del conflicto armado en Colombia, su persistencia y sus impactos. En Comisión Histórica del Conflicto y sus Víctimas (Ed.), Contribución al entendimiento del conficto armado en Colombia (pp. 407-450).

Godet, M. (1993). De la anticipación a la acción: manual de prospectiva y estrategia. Marcombo.

Godet, M. (2000). La caja de herramientas de la prospectiva estratégica (4.a ed.). GERPA.

Godet, M. (2006). Creating futures: Scenario planning as a strategic management tool (2. ${ }^{\mathrm{a}} \mathrm{ed}$.). Economica.

Godet, M., \& Durance, P. (2009, abril). La prospectiva estratégica para las empresas y los territorios (K. García, Trad.) (Cuaderno del Lipsor, Serie de Investigación n. ${ }^{\circ}$ 10). https://bit.ly/3oOciOP

Grasa, R., \& Mateos, O. (2014). Guía para trabajar en la construcción de la paz. Cómo afrontar el tránsito de "hacer las paces" a "construir la paz". Instituto Catalán Internacional para la Paz; Cámara de Comercio de Bogotá. http://hdl.handle.net/11520/14393

Grasa, R. (2020). Colombia cuatro años después de los acuerdos de paz: un análisis prospectivo (Documentos de Trabajo 39). Fundación Carolina. https://bit.ly/30nbpTS

Guglielmucci, A. (2017). El concepto de víctima en el campo de los derechos humanos: una reflexión crítica a partir de su aplicación en Argentina y Colombia. Revista de Estudios Sociales, 59, 83-97. https://doi. org/10.7440/res59.2017.07

Hevia, O. (2000). Metodología de escenarios: ¿utopía o concreción prospectiva en las ciencias sociales? Mundo Nuevo. Revista de Estudios Latinoamericanos, 87-90.

Hiltunen, E. (2009). Scenarios: process and outcome. Journal of Futures Studies, 13(3), 151-152. https:// bit.ly/3s0FCDI.

Jouvenel, B. (1964). L'art de la conjecture. Futuribles. Editions du Rocher.

Junguito, R., Perfetti, J. J., \& Delgado, M. (2017). Acuerdo de paz: reforma rural, cultivos ilícitos, comunidades y costo fiscal (Cuadernos de Fedesarrollo 55). http://hdl.handle.net/11445/3344.

Kahane, A. (2016). La planificación transformadora por escenarios. Trabajando juntos para cambiar el futuro. Comisión Nacional de los Derechos Humanos. https://bit.ly/3ILPzdQ

Kahn, H., \& Wiener, A. (1967). The year 2000: A framework for speculation on the next thirty-three years.

Khakee, A. (1991). Scenario construction for urban planning. International Journal of Management Science, 19(5), 459-469. https://doi.org/10.1016/0305-0483(91)90062-X

León-Mirabent, C., Rodríguez-Cruz, Y., Garrigó-Andreu, L., \& Soto-Balbón, M. A. (2020). Prospectiva estratégica en la Sociedad Cubana de Ciencias de la Información. Revista Publicando, 7(27), 38-53. https://bit.ly/3IJFIFp

Ley 1448. (2011). Por la cual se dictan medidas de atención, asistencia y reparación integral a las víctimas del conflicto armado interno y se dictan otras disposiciones. Congreso de la República de Colombia. https://bit.ly/3IMyTTy

Masini, E. B. (2011). How to teach futures studies: Some experiences. Journal of Futures Studies, 15(4), 111-120. https://bit.ly/31SgxjB

Matías Camargo, S. (2021). La Reforma Rural Integral, la terminación del conflicto armado y el problema agrario en Colombia. Revista Diálogos de Saberes, 46, 19-39. https://bit.ly/3rYrvyB

Medina Vásquez, J. (2003). Visión compartida de futuro. Universidad del Valle.

Miklos, T \& Tello, M, (2000). Planeación prospectiva. Una estrategia para el diseño del futuro. Centro de Estudios Prospectivos, Fundación Javier Barrios Sierra.

Ministerio de Justicia. (2018). Ruta Futuro: Politica integral para enfrentar el problema de las drogas 2018-2022. https://bit.ly/3mCb4V9 
Munévar M., S., Silva A., A., \& Sarmiento E., J. (2019). Exposición al conflicto armado y logro académico en Colombia. Revista Desarrollo y Sociedad, 83, 13-53. https://doi.org/10.13043/DYS.83.1

Pardo, D., Urbina, D., Arroyo, S., Forero, J., \& Arrieta, S. (2020). Los impactos del COVID-19 en la seguridad y en la implementación del Acuerdo de Paz. Los casos de Catatumbo, sur de Córdoba, Bajo Cauca y nordeste antioqueño. Fundación Ideas Para la Paz (FIP). https://bit.ly/3DTgZuF

Peña Torres, P. (2008). Prospectiva: una herramienta gerencial. Universidad Nacional de Colombia.

Peña Torres, P. (2020). Diseño de escenarios en la construcción de un proceso de paz en el CaquetáColombia [tesis doctoral]. Universidad de Baja California. México.

Peña, P., Valera, A., \& Marles, C. (2020). Tendencias en los procesos de construcción de paz. Revista Espacios 41(47). https://doi.org/10.48082/espacios-a20v41n47p21

Phadnis, S. S. (2012). Influencing managerial cognition and decisions using scenarios for long-range planning [tesis doctoral, Engineering Systems Division, Massachusetts Institute of Technology]. MIT Libraries. https://dspace.mit.edu/handle/1721.1/78483.

Pirateque, P. (2021). Los grupos armados residuales: la amenaza de los escenarios transformados en Colombia. Civilizar Estudiantil, 4(4), 43-62. http://hdl.handle.net/11232/1624

Pizarro, E. (2015). Una lectura múltiple y pluralista de la historia. En Comisión Histórica del Conflicto y sus Víctimas (Ed.), Contribución al entendimiento del conflicto armado en Colombia (pp. 5-99).

Porter, M. (2004). Competitive advantage: Creating and sustaining superior performance. Free Press.

Raymond, J. (2017). From combatants to candidates: Electoral competition and the legacy of armed conflict. ConflictManagementandPeaceScience,34(3),240-263.https://doi.org/10.1177/0738894215593676

Rettberg, A. (2003). Diseñar el futuro: una revisión de los dilemas de la construcción de paz para el post conflicto. Revista de Estudios Sociales, 15, 15-28. https://doi.org/10.7440/res15.2003.01

Rincón, T. (2010). Verdad, justicia y reparación: la justicia de la justicia transicional. Editorial Universidad del Rosario. http://repository.urosario.edu.co/handle/10336/13466

Ríos, J. \& González, J. C. (2021). Colombia y el Acuerdo de Paz con las FARC-EP: entre la paz territorial que no llega y la violencia que no cesa. Revista Española de Ciencia Política, 55, 63-91. https://doi. org/10.21308/recp.55.03.

Ríos-Sierra, J. (2020). ¿Una paz fallida? Dificultades de la construcción de paz en Colombia tras el acuerdo con las FARC-EP. Revista de Estudios Politicos, 190, 129-163. https://doi.org/10.18042/cepc/rep.190.05

Sandoval, D. (2017, mayo). Creemos en la necesidad de vivir en paz. Misión de Verificación de la ONU en Colombia. https://bit.ly/3GGq7EK

Schoemaker, P. J. (1993). Multiple scenario development: Its conceptual and behavioral foundation. Strategic Management Journal, 14(3), 193-213. https:/onlinelibrary.wiley.com/doi/abs/10.1002/ smj.4250140304

Schuck, A. M. (2017). Evaluating the impact of crime and discipline on student success in postsecondary education. Research in Higher Education, 58(1), 77-97. https://doi.org/10.1007/s11162-016-9419-x

Tiusabá Gómez, B., \& López, C. (2019). Elementos estructurales y coyunturales de una implementación conflictiva del Acuerdo de Paz entre el Gobierno colombiano y las FARC-EP. Estudios Políticos, 55, 224-244. http://doi.org/10.17533/udea.espo.n55a11

Torrijos Rivera, V. (2015). Cartografía del conflicto: pautas interpretativas sobre la volución del conflicto irregular colombiano. En Comisión Histórica del Conflicto y sus Víctimas (Ed.), Contribución al entendimiento del conflicto armado en Colombia (pp. 652-696).

Ulloa, A., \& Coronado, S. (2016). Territorio, Estado, actores sociales, derechos y conflictos socioambientales en contextos extractivistas: aportes para el posacuerdo. En A. Ulloa y S. Coronado (Eds.), Extractivismos y posconflicto en Colombia: retos para la paz territorial (pp. 23-58). Cinep; Universidad Nacional de Colombia. 
Unidad para la Atención y Reparación Integral a las Víctimas. (s. f.). Registro Único de Víctimas. Consultado el 12 de diciembre de 2021. https://bit.ly/3oWEfUJ

Uppsala Conflict Data Program (UCDP). (s. f.) Number of deaths. Colombia [base de datos]. https://ucdp. uu.se/encyclopedia. Consultado el 17 de septiembre de 2021.

Velandia, C. J., \& Paba, C. (2021). Resolución de conflictos, agresividad y factores sociodemográficos en víctimas del conflicto armado colombiano del Magdalena. Diversitas, 17(1). https://doi. org/10.15332/22563067.6541

Wright, W. (2004). Book review: Building peace: Sustainable reconciliation in divided societies [reseńa del libro Building peace: Sustainable reconciliation in divided societies de J. Lederach]. Armed Forces, 30(3), 491-495. https://doi.org/10.1177\%2F0095327X0403000311

Zahradnícková, L., \& Vacík, E. (2014). Scenarios as a strong support for strategic planning. Procedia Engineering, 69, 665-669. https://doi.org/10.1016/j.proeng.2014.03.040

Zubiría, S. de. (2015). Dimensiones políticas y culturales en el conflicto colombiano. En Comisión Histórica del Conflicto y sus Víctimas (Ed.), Contribución al entendimiento del conflicto armado en Colombia (pp. 194-247).

Zuluaga Nieto, J. (2004). La guerra interna y el desplazamiento forzado [documento sin edición]. https:// bit.ly/3m1gcSm 